\title{
PRONAF dez anos depois: resultados e perspectivas para o desenvolvimento rural
}

Carlos E. Guanziroli*

Resumo: Este artigo tenta efetuar uma avaliação da eficiência e eficácia do PRONAF (Programa de Fortalecimento da Agricultura Familiar) em gerar renda e melhoria de condições de vida para os agricultores familiares nos últimos dez anos da seguinte forma: comparamse para isto as liberações de crédito com o custo das mesmas para o Tesouro (abrangência versus custo), estuda-se a focalização do PRONAF e resumem-se 13 avaliações realizadas ao longo destes 10 anos por diversas instituições acadêmicas e por autores de diferente extração ideológica.

Palavras-chave: economia agrícola, avaliação de custos e eficiência, agricultura familiar

Classificação JEL: Q14, Q15, Q18

Abstract: The main goal of this article is to evaluate efficiency and efficacy of PRONAF (Program for the Strengthening of Family Farming) with respect to income generation and melioration of quality of life in the last

* Professor Adjunto da Universidade Federal Fluminense, Faculdade de Economia. PhD em Economia pela University College London (UCL). Pós PhD pela University of Califórnia, Santa Cruz. 2002, Ex Consultor FAO. guanzi@ism.com.br 
ten years in the following matter: Comparison credit allowances with treasury costs, analyzing focalization of PRONAF and resuming 13 evaluations made during last ten years by authors of different ideological and academic backgrounds.

Key words: agricultural economics, costs evaluation and efficiency, family farming

JEL Classification: Q14, Q15, Q18

\section{Introdução}

O PRONAF surge numa época (1995) na qual o elevado custo e a escassez de crédito eram apontados como os problemas principais enfrentados pelos agricultores, em particular os familiares. Após 10 anos de execução não cabe nenhuma dúvida que o programa se estendeu de forma considerável por todo o território nacional, ampliou o montante financiado, desenvolveu programas especiais para atender diversas categorias, assumiu a assistência técnica e reforçou a infraestrutura tanto dos próprios agricultores como dos municípios em que se encontra.

A quase totalidade dos subprogramas do PRONAF adotou, desde o início, uma política de remuneração bastante branda e com alto percentual de subsídio. A fixação da taxa de juros preferencial, subsidiada ou não, bem como o estabelecimento de outras condições especiais de pagamento e operação do crédito, tem várias justificativas e aspectos que merecem ser considerados.

$\mathrm{O}$ argumento central era que os produtores familiares, descapitalizados e com baixa produtividade, não estariam em condições de tomar recursos a taxas de mercado para realizar os investimentos em modernização e elevação da produtividade. Pelo menos na etapa inicial do processo de acumulação, seus investimentos não seriam rentáveis nem viáveis se avaliados pela taxa de juros de mercado; seus rendimentos também não seriam compatíveis nem suficientes para reembolsar empréstimos tomados em condições comerciais.

As condições de pagamento e de cobrança de juros são, portanto, 
determinantes da dinâmica do PRONAF. Dadas certas taxas de juros e demais condições, os produtores elegerão investimentos compatíveis com o pagamento do crédito.

A teoria econômica dá à taxa de juros um papel relevante em eficiência na utilização dos recursos: taxas muito baixas tenderiam a "afrouxar” o rigor na avaliação dos projetos e os recursos passariam a ser utilizados com menos rigor, pois o custo da ineficiência é relativamente baixo. Buainain (1997) descreve esta contradição da seguinte forma: “Taxas de juros mais elevadas produziriam melhor seleção dos projetos, já que apenas os mais rentáveis seriam compatíveis com o pagamento futuro do empréstimo. Os produtores também teriam que estar mais atentos à eficiência na utilização dos recursos. Ou seja, haveria uma tensão permanente entre crédito, taxa de juros, acumulação e eficiência econômica. Quando esta tensão cede demasiada para um lado, por exemplo, com redução de liquidez e taxas muito elevadas, compromete-se o processo de acumulação já que apenas alguns projetos gerarão fluxos de rendimentos futuros compatíveis com o pagamento dos juros; de outro lado, taxas muito baixas podem produzir desperdício de recursos escassos, seja pela má seleção de projetos seja pelo desvio ou má utilização dos recursos.” (pp 23).

As novas teorias geradas pela economia institucional permitiram perceber que outras variáveis, além da taxa de juros, desempenham papel fundamental no processo de utilização do crédito. Busca-se, na verdade, avaliar em que medida o contexto no qual estão inseridos os produtores e o próprio desenho institucional dos programas de crédito, induzem ou não o processo de acumulação e o uso eficiente dos recursos.

Trata-se, neste artigo, de avaliar eficiência e eficácia do PRONAF nos últimos 10 anos da seguinte forma: no primeiro capítulo comparam-se as liberações de crédito com o custo das mesmas para o Tesouro (abrangência versus custo); no segundo capítulo analisa-se a focalização do PRONAF, e no terceiro trata-se a questão do impacto resumindo um elenco de 13 avaliações realizadas ao longo destes 10 anos por diversas instituições acadêmicas e por autores de diferente extração ideológica. No final debatem-se as perspectivas de integração dos agricultores familiares nas cadeias produtivas e nas políticas de desenvolvimento territorial existentes hoje no Brasil. 


\section{Abrangência e custo do PRONAF}

Por tratar-se de uma política pública que envolve altos custos e subsídios, ela deve ser avaliada constantemente para justificar a sua existência.

A abrangência do programa, no que tange às liberações totais do PRONAF, apresentou um movimento ascendente entre 2000 e 2005 (Tabela 1). De fato, passou-se de uma liberação de $\mathrm{R} \$ 2.189$ milhões para R\$ 6.300 milhões. Esta é uma modificação da tendência que se verificava anteriormente, visto que a partir de 1999 o Programa começou a apresentar certa estagnação na liberação de recursos.

Um dos maiores entraves para o crescimento do PRONAF tem sido o setor bancário público, responsável pela liberação dos recursos do PRONAF Crédito, que resiste à ampliação da sua clientela. Este problema teria sido em parte solucionado com a atuação dos Fundos de Aval que permitiram que se aumentasse a participação dos beneficiários no acesso aos recursos.

Na verdade, conforme reconhece o próprio Relatório Institucional do PRONAF (2002), os bancos são organizações pouco adequadas para liberar recursos a famílias sem condições de lhes oferecer garantias patrimoniais e contrapartidas na tomada dos empréstimos. Petrelli, V. (2004) observa que a segmentação do Programa tem provocado impactos interessantes no sentido de que um número crescente de organizações locais ter se envolvido na busca de organizar esquemas de garantia de crédito e também no auxílio aos bancos em tarefas administrativas que ajudam na concessão de crédito. Gera-se paulatinamente uma rede de agentes que envolvem os sindicatos (que atestam o fato de o demandante do crédito ser um agricultor familiar), equipes de prefeituras, além de agentes envolvidos com apoio e monitoramento.

As liberações de recursos para os agricultores têm, em contrapartida, um custo para o Tesouro, dado pela necessidade de equalizar com recursos do Orçamento a diferença entre os juros cobrados aos beneficiários (entre $1 \%$ e $9 \%$ a/a) e a taxa SELIC. O montante destinado à equalização dos juros (Decreto $n^{\circ}$. 1.946 de 28/01/1996) embora declinante, continua bastante alto se comparado com outras políticas agrícolas. Em média $44,5 \%$ do valor liberado destina-se a equalizar juros e rebates de adim- 
plência conforme pode se observar na Tabela 1. Trata-se, portanto de um programa caro e altamente subsidiado que, por isso, deve ser bem avaliado e ter indicadores de resultados que comprovem sua necessidade.

Tabela 1 - Recursos Liberados do PRONAF e Valor das Equalizações

\begin{tabular}{|c|c|c|c|c|}
\hline Ano & $\mathrm{N}^{\circ}$ Contratos (a) & $\begin{array}{l}\text { Montante Crédito } \\
(\mathrm{R} \$ \text { milhão) (b) }\end{array}$ & Equalizações (c ) & $\mathrm{C} / \mathrm{b} \%$ \\
\hline 2000 & 969.000 & 2.189 & 1.191 & 54,4 \\
\hline 2001 & 910,000 & 2.153 & 1.268 & 58,8 \\
\hline 2002 & 953.000 & 2.405 & 1.447 & 60,1 \\
\hline 2003 & 1.138 .000 & 3.807 & 1.594 & 41,8 \\
\hline 2004 & 1.611 .000 & 5.747 & 2.794 & 48,6 \\
\hline 2005 & 1.800 .000 & 6.300 & 1.782 & 28,2 \\
\hline TOTAL & 7.381 .000 & 22.601 & 10.076 & 44,5 \\
\hline
\end{tabular}

Fonte: Contratos e Montante: Mattei, L (2006) . Equalização: Gasques et al. (2006)

Além da equalização existe o custo que os Bancos cobram como overhead para emprestar os recursos. O OGU (Orçamento Geral da União) prevê o pagamento aos Bancos pelo seu trabalho de intermediação. Em 2002, para cada empréstimo de custeio dos Grupos C e D o banco recebia $8,99 \%$ aa mais uma taxa de administração mensal para cada contrato. No mesmo ano o custo médio por operação girava em torno de $17,83 \%$ aa do total emprestado. O Banco do Nordeste paralelamente recebia uma taxa média de $11,97 \%$ aa. (Petrelli, V.2004, pp 6).

Abramovay, R. (2002) estima valores mais altos para a mesma finalidade: "Para fazer um empréstimo de $\mathrm{R} \$ 1.300,00$ o Tesouro gasta R\$ 544,36. Desse gasto do Tesouro, a metade vai para o agricultor, sob a forma de rebate por pagamento em dia e subsídio à taxa de juros. A outra metade vai para o Banco do Brasil, a título de spread e de taxa de serviço. Para cada real emprestado a esta categoria de produtores, o Tesouro gasta quarenta e um centavos, dos quais a metade com a intermediação bancária.” (pp. 3).

Teixeira, Erly (2004) calcula que cada real gasto com a equalização gera um crescimento no PIB equivalente a 1,75 vez o gasto com a Equalização da Taxa de Juros (ETJ) na agricultura familiar (AF), e 3,57 vezes o gasto com a ETJ na agricultura comercial (AC). Haveria um aumento na arrecadação de impostos de $16,9 \%$ do gasto com a ETJ na agricultu- 
ra familiar, e de $37,0 \%$ do gasto com a ETJ na agricultura comercial. Ou seja, os gastos governamentais com a ETJ seriam parcialmente recuperados com o aumento na arrecadação de impostos.

O multiplicador encontrado para a AC é o dobro do multiplicador da AF. Segundo Teixeira: "A principal razão para isso é o fato de a agricultura comercial pagar juros mais altos e, portanto, apresentar custo de equalização menor. Para dada dotação de recursos, o volume disponibilizado de recursos para AC é maior que o disponibilizado para a AF e, conseqüentemente, os efeitos na economia também são maiores que os proporcionados pela AF. No entanto, os recursos aplicados mediante equalização das taxas de juros na AF geram efeitos positivos relevantes no crescimento da economia.”(pág. 9).

Em suma, os recursos liberados pelo PRONAF vêm aumentando, conjuntamente, como o custo que isso representa para o Tesouro. Resta avaliar a efetividade deste crédito no processo de geração de renda para os agricultores familiares e no aumento da produção agrícola para o país.

\section{Focalizaçao nos diferentes grupos de renda e nas regiões}

Uma das principais críticas feitas ao PRONAF tem sido em relação a um suposto erro ou desvio de foco em relação a algo considerado como ideal de distribuição, em termos regionais e sociais.

Quem melhor resume esta crítica é Petrelli, V. (2004) quando observa que, "no leque do universo considerado como sendo o de agricultores familiares o grupo mais economicamente integrado tem recebido as benesses desta integração e conseguiu fazer parte do processo de modernização conservadora. Podemos verificar a alta participação das liberações para fumo e soja sobre o total financiado, lembrando que estes produtos têm ligação direta com a produção agroindustrial e de exportação. Paralelamente, verificamos a baixíssima participação de liberações para a produção de arroz, feijão e outros produtos dirigidos ao mercado interno. Haveria também domínio quase que total dos recursos na região Sul nos primeiros anos de implantação do PRONAF que estaria sendo contrabalançado nos anos posteriores.” (pp 7).

Petrelli (2004 op cit) diz que o Programa estaria privilegiando, na 
verdade, a propriedade familiar "eficiente" em detrimento dos mais fragilizados: pelos dados disponíveis não teriam sido os agricultores do estrato B do projeto FAO/INCRA os mais privilegiados com recursos e sim os do estrato A.

Ao analisar o conjunto ter-se-ia de um lado um PRONAF-Infraestrutura que não apresentaria uma expansão consistente na liberação de recursos, mas que atinge as necessidades dos agricultores familiares mais carentes e, de outro, o PRONAF-Crédito que expandiria seus beneficiários potenciais, mas que não consegue mudar sua lógica de liberação.

Segundo Schneider (2004) "A especialização produtiva gerada pelo PRONAF é a situação em que o agricultor familiar é levado, pela política pública, a plantar o que esta financia. Ou seja, o que é mais fácil e historicamente as instituições bancárias tem tradição de financiamento e de operacionalização" (pág 6). Ou seja, o programa continuaria a fazer mais do mesmo, o que significa continuar financiando o padrão de desenvolvimento vigente.

Lauro Mattei (2006) em trabalho recente encomendado pela SAF fornece informações importantes que revelam que não houve mudança significativa na tendência concentradora descrita antes por Petrelli. Segundo Mattei “Em termos do montante de recursos disponível para cada região geográfica do país, nota-se que, na safra de 1999 , quase $50 \%$ dos recursos do programa se concentravam na região Sul, enquanto que a região Nordeste respondia por $26 \%$; a Sudeste, por $16 \%$; a Centro-Oeste, $5 \%$; e a região Norte, por apenas $3 \%$ do total. Teriam ocorrido algumas alterações, na safra de 2004, porém sem as mudanças necessárias na rota do programa para que efetivamente se transforme em uma política de apoio ao desenvolvimento rural em todas as regiões do país. Assim, percebe-se que, mesmo havendo uma redução dos contratos na região Sul, ela continua concentrando $47 \%$ do total dos recursos do programa, enquanto que a região Nordeste diminuiu sua participação de $26 \%$, em 1999 , para $18 \%$ na última safra agrícola, mesmo que um maior número de agricultores tenha tido acesso ao crédito rural. As regiões Sudeste e Centro-Oeste aumentaram a participação em um ponto percentual e a região Norte aumentou sua participação no volume total dos recursos para $12 \%$ ”, (pág.18). 
Tabela 2 - Distribuição Regional dos Recursos do PRONAF

\begin{tabular}{|l|l|l|}
\hline Região & \multicolumn{1}{|c|}{$\begin{array}{c}\text { Percentual de } \\
\text { Recursos 1999 }\end{array}$} & \multicolumn{1}{c|}{$\begin{array}{c}\text { Percentual de } \\
\text { Recursos 2004 }\end{array}$} \\
\hline Norte & 3 & 12 \\
\hline Nordeste & 26 & 18 \\
\hline Centro- Oeste & 5 & 6 \\
\hline Sul & 50 & 47 \\
\hline Sudeste & 16 & 17 \\
\hline
\end{tabular}

Fonte: Dados extraídos de Mattei, L (2006)

Do ponto de vista do montante de recursos destinado às diversas categorias, os dados de Mattei não revelam que tenha havido grandes alterações. Assim, na safra de 1999, os agricultores enquadrados no grupo D respondiam por $48 \%$ do total e os do grupo C, por $22 \%$, revelando que essas duas categorias detinham cerca de $70 \%$ do total do crédito disponibilizado pelo programa. O grupo A respondia por $21 \%$; o grupo B, por apenas $1 \%$ (primeiro ano de operação dessa modalidade); e o restante dizia respeito aos contratos sem enquadramento definido. Na safra agrícola de 2004, essa trajetória mudou um pouco, sobretudo pela maior participação do grupo B, que passou a responder por $7 \%$ do total, ao mesmo tempo em que o grupo D reduzia sua participação em $11 \%$ e o grupo A em $13 \%$. O grupo C aumentou sua participação para $25 \%$. O fato mais relevante é que o processo de concentração dos recursos nos grupos C, D e E continua expressivo, que passaram a responder por $74 \%$ do total dos recursos disponibilizados na última safra.

Quanto à distribuição do montante de recursos por modalidade de crédito, a proporção entre as duas modalidades permanece praticamente estável, ou seja, o montante total do crédito de custeio ao longo do período considerado corresponde a duas vezes o total do crédito de investimento, embora este último venha melhorando sua participação no volume total.

Segundo Murilo Flores (citado em Marques, 2005), esta propensão teria sido prevista pela equipe responsável pela implantação do PRONAF que sabia que o sistema financeiro não seria acessível aos agricultores familiares mais marginalizados, e por isso teria adotado uma estratégia no início de encorajar os agricultores situados mais no topo da escala 
da modernização a reivindicar outro modelo de desenvolvimento. O acesso facilitado ao crédito poderia favorecer a mobilização. Num segundo momento, os gestores do PRONAF cogitavam que a emergência de uma camada pujante de agricultores familiares poderia beneficiar o conjunto da categoria (efeito spill over).

Tabela 3 - Distribuição do PRONAF por categorias de renda

\begin{tabular}{|l|l|l|}
\hline Categoria & Percentual 1999 & Percentual 2004 \\
\hline A & 21 & 13 \\
\hline B & 1 & 7 \\
\hline C & 22 & 25 \\
\hline D & 48 & 37 \\
\hline E & (Outros) & 12 \\
\hline
\end{tabular}

Fonte: Dados Extraídos de Mattei (2006)

De fato o projeto FAO/INCRA (1994) no documento conhecido como "Diretrizes de Política Agrária Sustentável” propunha políticas diferenciadas para as diferentes categorias da agricultura familiar, privilegiando com crédito de infra-estrutura aos agricultores em transição e com políticas agrárias e sociais aos periféricos, que deveriam em função disso, tentar ascender à categoria B. Isto era fundamentado na realidade existente na agricultura familiar em termos de renda monetária como revela a tabela que segue:

Tabela 4 - Agricultores Familiares - Renda monetária (RM) por estabelecimento segundo os tipos familiares

\begin{tabular}{|c|l|l|l|}
\hline Tipos & \multicolumn{1}{|c|}{$\begin{array}{c}\text { Estab. } \\
\text { Total }\end{array}$} & $\begin{array}{c}\text { \% Estab. } \\
\text { s/ total }\end{array}$ & $\begin{array}{c}\text { RM / Estab. } \\
\text { (Em R\$/ano) }\end{array}$ \\
\hline A & 406.291 & 8,4 & $\mathbf{1 1 . 8 9 8}$ \\
\hline B & 993.751 & 20,4 & $\mathbf{2 . 1 7 2}$ \\
\hline C & 823.547 & 16,9 & $\mathbf{7 1 4}$ \\
\hline D & 1.915 .780 & 39,4 & $\mathbf{( 1 0 4 )}$ \\
\hline Total & $\mathbf{4 . 1 3 9 . 3 6 9}$ & $\mathbf{8 5 , 1}$ & \\
\hline
\end{tabular}

Fonte: Censo Agropecuário 1995/96 - IBGE

Elaboração: FAO/INCRA (2000). Projeto de Cooperação Técnica.

Guanziroli, C. et al. (2001). 
Percebe-se acima que mais da metade (56\%) dos estabelecimentos da agricultura familiar não conseguia, em 1996, obter uma renda mínima anual unicamente por meio de seus estabelecimentos (varia de $\mathrm{R} \$$ 714 a/a a um valor negativo de $\mathrm{R} \$ 104$ ). Para sobreviver, muitos agricultores familiares dependiam de rendas externas ao estabelecimento agrícola, como aposentadorias, venda de serviços em outros estabelecimentos (familiares e patronais) ou atuando em atividades não agrícolas. Como o Censo Agropecuário levanta apenas a renda familiar obtida dos próprios estabelecimentos agropecuários, não considerando as receitas não agrícolas, previdenciárias ou mesmo da venda de serviços de mão-de-obra, este tipo de renda é a explicação para a sobrevivência dos agricultores familiares do tipo $D$.

Nos estabelecimentos familiares mais pobres, em especial aqueles voltados à produção de subsistência, é comum encontrar casos em que a Renda Monetária é negativa. Entretanto, geralmente a Renda Total do estabelecimento é positiva, pois inclui o autoconsumo. Muitos destes agricultores investem recursos monetários externos aos estabelecimentos, principalmente de venda de serviços e de aposentadoria, para gerar alimentos destinados ao seu consumo, os quais, apesar de não garantir renda monetária direta com sua venda, custam muito menos do que o agricultor gastaria para comprá-los no comércio. Esta afirmação justifica alguns dos motivos que explicam a renda monetária negativa entre os agricultores do grupo D.

Ao considerar a situação destes agricultores antes do inicio do PRONAF fica evidente que parte deles, embora classificados como estabelecimentos pelo IBGE, não eram verdadeiros agricultores. Segundo uma pesquisa do IBASE (citada por Bittencourt, 2002), 50\% dos agricultores que tomaram crédito pelo PRONAF nunca tinham anteriormente realizado uma operação de financiamento bancário.

Uma política de crédito focalizada nos setores mais carentes do meio rural poderia ser um contra-senso, já que eles não têm atividade que sustente ou demande esse tipo de política. Seria o crédito o melhor instrumento para modificar a realidade de exclusão social da agricultura? Qual é o sentido de dar crédito a quem não tem renda monetária? Por esse motivo, a proposta de 1996 (FAO/INCRA) afirmava que esses grupos (os C e D) deveriam ser alvo de políticas agrárias e sociais e não de crédito. 
A situação de exclusão estrutural dos setores periféricos aparece mais clara ainda ao se considerar os dados de assistência técnica e de infra-estrutura existentes na agricultora familiar na época que começou o PRONAF, como revela a tabela que segue:

Tabela 5 - Agricultores Familiares - Acesso à tecnologia e à assistência técnica

\begin{tabular}{|c|c|c|c|c|c|c|c|}
\hline \multirow[b]{2}{*}{ REGIÃO } & \multirow{2}{*}{$\begin{array}{l}\text { Utiliza } \\
\text { Assist. } \\
\text { Técnica } \\
\end{array}$} & \multirow{2}{*}{$\begin{array}{c}\text { Usa } \\
\text { Energia } \\
\text { Elétrica }\end{array}$} & \multicolumn{3}{|c|}{ Uso de força nos trabalhos } & \multirow[b]{2}{*}{$\begin{array}{l}\text { Usa Adubos } \\
\text { e Corretivos }\end{array}$} & \multirow{2}{*}{$\begin{array}{c}\text { Faz } \\
\text { Conserv. } \\
\text { do solo }\end{array}$} \\
\hline & & & \begin{tabular}{|c|} 
Só \\
animal
\end{tabular} & $\begin{array}{c}\text { Só mecânica ou } \\
\text { mecânica + animal }\end{array}$ & Manual & & \\
\hline Nordeste & 2,7 & 18,7 & 20,6 & 18,2 & 61,1 & 16,8 & 6,3 \\
\hline C. Oeste & 24,9 & 45,3 & 12,8 & 39,8 & 47,3 & 34,2 & 13,1 \\
\hline Norte & 5,7 & 9,3 & 9,3 & 3,7 & 87,1 & 9,0 & 0,7 \\
\hline Sudeste & 22,7 & 56,2 & 19,0 & 38,7 & 42,2 & 60,6 & 24,3 \\
\hline Sul & 47,2 & 73,5 & 37,2 & 48,4 & 14,3 & 77,1 & 44,9 \\
\hline BRASIL & 16,7 & 36,6 & 22,7 & 27,5 & 49,8 & 36,7 & 17,3 \\
\hline
\end{tabular}

Fonte: Censo Agropecuário 1995/96 - IBGE

Elaboração: Projeto de Cooperação Técnica INCRA/FAO

Como se pode perceber, apenas $16,7 \%$ dos agricultores familiares tinham assistência técnica na época, e quase a metade deles trabalhava com uso apenas de força manual, ou seja, “na enxada”. Esta situação é ainda muito pior quando os dados são desagregados por categorias de renda. Ou seja, antes que crédito, era necessário resolver questões básicas que permitissem a estruturação de um estabelecimento verdadeiramente agropecuário, o que inclui, além dos temas acima assinalados, também as questões educacional, da terra e da saúde, que também revelavam índices extremamente baixos entre os agricultores periféricos.

Não haveria, portanto, nenhum erro de focalização segundo nosso ponto de vista.

Outro argumento era que o financiamento dirigido aos agricultores mais integrados poderia fragilizar este setor que, se financiado, especializar-se-ia em poucos produtos da monocultura e expor-se-ia exageradamente às forças do mercado. A maior mercantilização, entretanto, ao invés de fragilizar o agricultor familiar, o fortalece, como revelam os dados expostos na tabela que segue:

A maioria dos agricultores familiares possui uma produção diversificada ou especializada, sendo que apenas $11,5 \%$ de seus estabelecimen- 
tos apresentam uma produção muito especializada, em que um único produto atinge $100 \%$ do valor bruto de sua produção. O sistema mais freqüente é o diversificado, com $44,1 \%$ dos estabelecimentos tendo um único produto atingindo de $35 \%$ a $65 \%$ do VBP. Os agricultores especializados, representados por $29,4 \%$ do total são, entretanto, os que obtêm a maior renda total, tanto por estabelecimento quanto por unidade de área, sendo $\mathrm{R} \$ 3.885$ por estabelecimento e $\mathrm{R} \$ 139$ por hectare.

Tabela 6 - Brasil - Agricultores Familiares - Estabelecimentos, \% do VBP, RT/ estab. e RT por ha (Em R\$), segundo o grau de especialização da produção ( $\left.{ }^{1}\right)$

\begin{tabular}{|l|c|c|c|c|c|c|}
\hline \multicolumn{1}{|c|}{ TIPOS } & Estab. & \% Estab. & \% Área & \% VBP & RT / Estab. & RT / Ha \\
\hline FAMILIAR & \multicolumn{7}{|c|}{} \\
Muito especializado & 476.806 & 11,5 & 8,7 & 9,6 & 2.113 & 108 \\
Especializado & 1.217 .412 & 29,4 & 31,5 & 44,5 & 3.885 & 139 \\
Diversificado & 1.825 .994 & 44,1 & 44,7 & 36,8 & 2.379 & 90 \\
Muito diversificado & 526.420 & 12,7 & 12,4 & 9,1 & 2.331 & 92 \\
FAMILIAR & & & & & & \\
Muito integrado & 799.911 & 19,3 & 21,6 & 38,8 & 4.604 & 158 \\
Integrado & 1.422 .675 & 34,4 & 37,4 & 37,2 & 3.058 & 108 \\
Pouco integrado & 1.824 .046 & 44,1 & 38,2 & 24,0 & 1.795 & 80 \\
\hline
\end{tabular}

Fonte: Censo Agropecuário 1995/96 - IBGE

Elaboração: Projeto de Cooperação Técnica INCRA/FAO. Guanziroli et al. (2001).

Os agricultores familiares muito integrados ao mercado são os que apresentam maior renda média por estabelecimento e por hectare representadas por $\mathrm{R} \$ 4.604$ e $\mathrm{R} \$ 158$, respectivamente, além de serem responsáveis por $38,8 \%$ do VBP da agricultura familiar, mesmo dispondo de apenas $21,6 \%$ da área.

Pode-se perceber então que os agricultores que possuem um sistema de grau de especialização alto e forte integração nos mercados, com uma média de $65 \%$ a $90 \%$ do VBP em um produto e o resto diversificado, são os que geram maiores rendas por hectare e também totais por estabelecimento. Os produtores mais integrados no mercado também foram os que obtiveram as maiores rendas agrícolas, contrariamente à

\footnotetext{
${ }^{1}$ A diferença em relação ao percentual de $100 \%$ refere-se aos casos não identificados, os quais ocorrem quando não existe Valor Bruto da Produção (VBP) declarado.
} 
teoria que apregoa a diversificação como a mais eficiente e critica a especialização por ser mais "fragilizadora". O perfil típico de um agricultor familiar eficiente é aquele que destina $70 \%$ da área para produzir no máximo dois produtos e o restante para uma agricultura diversificada.

Em suma, a maior destinação de recursos do PRONAF aos agricultores mais especializados e de rendas mais altas (entre os agricultores familiares) é coerente com a realidade da agricultura familiar e com a demanda de crédito existente entre as diferentes categorias. Essa demanda, uma vez atendida, logicamente acabou sendo investida preferencialmente em produtos da monocultura como soja, milho e fumo em regiões desenvolvidas do país (Sul e Centro Oeste) como se viu nas tabelas anteriormente expostas. A concentração aconteceu de forma natural, na medida em que não houve nenhum direcionamento do crédito para atender cadeias produtivas específicas diferentes das demandantes. Houve uma captura do PRONAF por setores de renda mais alta ligados à monocultura que também se aproveitaram do seguro de safra, como acontecera na safra de 2005/06, em valores bastante significativos.

A visão de cadeias produtivas (ou sistemas) pretende que o crédito atenda cadeias selecionadas a priori em regiões determinadas também em função de uma ordem de prioridades definida de forma conjunta entre a sociedade e o governo, em função da necessidade e interesse do governo em desenvolvê-las e fortalecê-las. Estas cadeias não necessariamente deveriam coincidir com os setores que mais demandam crédito.

A alocação espontânea deixa em aberto o interrogante sobre o efeito que o crédito recebido pelas camadas de renda mais alta possa ter (efeito spill over) sobre outras categorias. Na melhor das hipóteses pode se supor que tenha aumentado a demanda por emprego para ser atendido pelos periféricos, e espera-se também que outras políticas sociais e agrárias (educação, saúde, fome zero, atividades rurais não agrícolas e reforma agrária) tenham conseguido integrar uma parte dos agricultores periféricos no sistema agroindustrial.

\section{Avaliação dos resultados do PRONAF Crédito}

Como disséramos no início deste artigo busca-se avaliar o impacto que o PRONAF teve em termos de crescimento da renda, representado 
pelo crescimento no valor da produção, e crescimento na capacitação do agricultor familiar, representado pelo crescimento no valor da produção por hectare e por pessoa engajada na produção.

A maior parte das pesquisas encontradas sobre o tema buscava mais uma avaliação de processo do que a aferição de impacto propriamente dita. Tampouco foi possível encontrar muitas avaliações de impacto que tenham incluído no grupo controle o contrafactual necessário para poder comparar efeitos do programa sobre beneficiados e não beneficiados. Não encontramos pesquisas que tenham adotado a metodologia de painel que permita comparar no tempo a evolução de um grupo de agricultores beneficiados.

A pesar destas limitações foi possível selecionar um elenco de 13 pesquisas que trazem dados relacionados com o impacto do PRONAF na renda, tanto de âmbito regional como nacional. 
Segue a continuação uma síntese dos resultados das pesquisas selecionadas:

\begin{tabular}{|c|c|c|c|}
\hline $\begin{array}{l}\text { Instituição } \\
\text { /autor }\end{array}$ & Amostra & Resultados & $\begin{array}{c}\text { Problemas e Soluçoes } \\
\text { Propostas }\end{array}$ \\
\hline $\begin{array}{l}\text { 1- LUMEN Insti- } \\
\text { tuto de Pesquisa } \\
\text { da PUC/MG } \\
\text { (1997) }\end{array}$ & $\begin{array}{l}550 \text { question- } \\
\text { ários na Zona } \\
\text { Sul da Mata de } \\
\text { MG. } 110 \text { com } \\
\text { beneficiários. }\end{array}$ & $\begin{array}{l}(41,2 \%) \text { responderam } \\
\text { ter obtido aumento } \\
\text { na produção; }(20,6 \%) \\
\text { aumentaram a renda; } \\
(14,7 \%) \text { aumentaram a } \\
\text { produtividade e }(5,9 \%) \\
\text { afirmaram ter obtido } \\
\text { regularidade no plantio. }\end{array}$ & $\begin{array}{l}\text { São agricultores mais } \\
\text { bem informados, mais } \\
\text { abastados e com maior } \\
\text { grau de associativismo } \\
\text { que a média regional. }\end{array}$ \\
\hline $\begin{array}{l}\text { 2- Instituto } \\
\text { de Pesquisa } \\
\text { Econômica } \\
\text { Aplicada - IPEA } \\
\text { Abramovay e } \\
\text { Veiga (1998) }\end{array}$ & $\begin{array}{l}\text { Pesquisa de } \\
\text { campo em } 8 \\
\text { estados com } 16 \\
\text { municípios. }\end{array}$ & $\begin{array}{l}\text { Poço Verde (SE) } \\
\text { colheu } 20 \text { mil tonela- } \\
\text { das de milho, } 10 \text { mil } \\
\text { toneladas de feijão, } \\
\text { e o valor total da } \\
\text { produção agropecuária } \\
\text { (R\$ } 6 \text { milhões) per- } \\
\text { mitiram uma arrecada- } \\
\text { ção de ICMS de R\$ } 400 \\
\text { mil, } 30 \% \text { a mais que } \\
\text { na safra sem PRONAF. } \\
\text { Concentração de recur- } \\
\text { sos na região Sul e na } \\
\text { agroindústria de fumo. }\end{array}$ & $\begin{array}{l}\text { Operacionalização do } \\
\text { programa por um fundo } \\
\text { de aval, com a participa- } \\
\text { ção de agricultores. } \\
\text { Liberação dos recursos } \\
\text { que passe diretamente } \\
\text { da instância federal para } \\
\text { a municipal. }\end{array}$ \\
\hline $\begin{array}{l}\text { 3- FAVERO, Luiz } \\
\text { e Fábio José } \\
\text { Alves (2002) Pes- } \\
\text { quisa do Fórum } \\
\text { Nacional de Séc } \\
\text { Agric. (1999) }\end{array}$ & $\begin{array}{l}15 \text { entrevis- } \\
\text { tas Região } \\
\text { do Agreste } \\
\text { Pernambu } \\
\text { cano }\end{array}$ & $\begin{array}{l}80 \% \text { dos agricultores } \\
\text { familiares afirmam } \\
\text { que houve aumento } \\
\text { da área plantada } \\
\text { (Investimento). } 40 \% \\
\text { aumentou o número de } \\
\text { pessoas ocupadas na } \\
\text { família e o crescimento } \\
\text { de } 80 \% \text { na contratação } \\
\text { de terceiros. Pequena } \\
\text { melhora no padrão de } \\
\text { vida dos agricultores } \\
\text { familiares. }\end{array}$ & $\begin{array}{l}\text { Crédito investimento } \\
\text { que ainda tem que } \\
\text { dar retornos para } \\
\text { ser avaliado melhor. } \\
\text { Baixa compreensão da } \\
\text { formação dos custos de } \\
\text { produção, e um baixo } \\
\text { interesse no gerencia- } \\
\text { mento. Necessidade de } \\
\text { capacitação para gestão } \\
\text { do agronegócio da agri- } \\
\text { cultura familiar. }\end{array}$ \\
\hline
\end{tabular}




\begin{tabular}{|c|c|c|c|}
\hline $\begin{array}{l}\text { 4-MAGA } \\
\text { LHÃES André } \\
\text { Matos; Filizzola } \\
\text { Mário (2005) } \\
\text { com base em } \\
\text { pesquisa de } \\
(2001)\end{array}$ & $\begin{array}{l}6.100 \text { agricul- } \\
\text { tores, } 2 / 3 \text { que } \\
\text { receberam e } \\
1 / 3 \text { que não } \\
\text { receberam } \\
\text { PRONAF em } \\
133 \text { municípios } \\
\text { do Paraná. }\end{array}$ & $\begin{array}{l}\text { Controlando pelas } \\
\text { características dos } \\
\text { participantes (OLS) } \\
\text { dá impacto positivo } \\
\text { de R } \$ 437 \text { no valor } \\
\text { de produção e de } \mathrm{R} \$ \\
80 \text { per capita. Com } \\
\text { método de Propensity } \\
\text { Score dá negativo de } \\
\mathrm{R} \$ 1.820 \text { e de } 42 \text { per } \\
\text { capita. Só da positivo } \\
\text { no D de R\$ } 2647 \\
\text { e R } \$ 852 \text { na per capita. }\end{array}$ & $\begin{array}{l}\text { O impacto do PRONAF } \\
\text { na renda e na produ- } \\
\text { tividade seria modesto. } \\
\text { A baixa integração nos } \\
\text { mercados seria um dos } \\
\text { fatores. Estaria atingindo } \\
\text { seus objetivos só em } \\
\text { algumas áreas do país } \\
\text { (Sul principalmente e } \\
\text { entre os integrados). }\end{array}$ \\
\hline $\begin{array}{l}\text { 5- MAGALHÃES } \\
\text { André Matos et } \\
\text { al. (2005) pes- } \\
\text { quisa de (2001) }\end{array}$ & $\begin{array}{l}4.500 \text { quest. } \\
\text { em PE, com } \\
\text { pequenos ag- } \\
\text { ricultores, } 2 / 3 \\
\text { beneficiários } \\
\text { do PRONAF } \\
1 / 3 \text { não } \\
\text { beneficiário } \\
\text { Pesquisa } \\
\text { de campo } \\
\text { realizada pela } \\
\text { FADE-UFPE. }\end{array}$ & $\begin{array}{l}\text { O impacto do pro- } \\
\text { grama sobre o valor da } \\
\text { produção por hectare } \\
\text { o efeito foi nega- } \\
\text { tivo em torno de } \mathrm{R} \$ \\
345,00 \text {. As do grupo } \\
\mathrm{D} \text { (maiores rendas) } \\
\text { tiveram efeito positivo } \\
\text { na produção(ha). }\end{array}$ & $\begin{array}{l}\text { Pode haver um conflito } \\
\text { entre a necessidade de } \\
\text { financiar agricultores } \\
\text { familiares que têm, ou } \\
\text { podem vir a ter par- } \\
\text { ticipação nos mercados, } \\
\text { mas também objetiva } \\
\text { política social sobre todo } \\
\text { o grupo de agricultores } \\
\text { familiares. }\end{array}$ \\
\hline $\begin{array}{l}\text { 6- FEIJÓ Ricardo } \\
\text { L.C. (2001) }\end{array}$ & $\begin{array}{l}\text { Dados } \\
\text { secundários de } \\
\text { IBGE (PAM), } \\
\text { PRONAF, FGV } \\
\text { técnicas de } \\
\text { pareamento } \\
\text { Tornqvist-Theil }\end{array}$ & $\begin{array}{l}\text { Favorecidos pelo } \\
\text { PRONAF têm baixo } \\
\text { crescimento de produ- } \\
\text { tividade de } 2,03 \% \text {, o } \\
\text { grupo de controle tem } \\
\text { desempenho superior: } \\
3,61 \% \text {. }\end{array}$ & $\begin{array}{l}\text { Beneficiados pelo PRO- } \\
\text { NAF têm crescimento } \\
\text { da produtividade acima } \\
\text { do grupo de controle em } \\
1997 \text { e nos anos mais } \\
\text { recentes de } 2000 \text { e } 2001 \text {, } \\
\text { o que sugere que o pro- } \\
\text { grama começa a surtir } \\
\text { impacto produtivo. }\end{array}$ \\
\hline $\begin{array}{l}\text { 7- FECAMP } \\
(2002)\end{array}$ & $\begin{array}{l}1.994 \text { produ- } \\
\text { tores rurais: } 1 / 2 \\
\text { beneficiados } \\
\text { e } 1 / 2 \text { não em } 8 \\
\text { estados (Sul e } \\
\text { NE). }\end{array}$ & $\begin{array}{l}\text { Efeito negativo sobre } \\
\text { a renda dos domicí- } \\
\text { lios: Produtores com } \\
\text { financiamento apre- } \\
\text { sentam renda média } \\
20,31 \% \text { menor que o } \\
\text { grupo sem acesso. }\end{array}$ & $\begin{array}{l}\text { A relação negativa pode } \\
\text { ser decorrente do fato } \\
\text { de serem os agricultores } \\
\text { mais pobres os que } \\
\text { recorrem aos financia- } \\
\text { mentos desse Programa. }\end{array}$ \\
\hline
\end{tabular}




\begin{tabular}{|c|c|c|c|}
\hline $\begin{array}{l}\text { 8-SACCO DOS } \\
\text { ANJOS Flavio } \\
\text { (FECAMP 2002) }\end{array}$ & $\begin{array}{l}200 \text { questio } \\
\text { nários em Rio } \\
\text { Grande do Sul }\end{array}$ & $\begin{array}{l}\text { Positivo: Mas se para } \\
\text { o conjunto de PRONA- } \\
\text { Fianos a renda média } \\
\text { ficou em R } \$ 8.553 \text {, } \\
\text { para os não-PRONAFi- } \\
\text { anos ela é } R \$ 7.125,00 \text {. }\end{array}$ & $\begin{array}{l}\text { O subgrupo D dos } \\
\text { PRONAFianos possuem } \\
\text { índice mais elevado en- } \\
\text { tre todos os subtipos. Há } \\
\text { uma clara diferenciação } \\
\text { social entre os PRO- } \\
\text { NAFianos. Dever-se-ia } \\
\text { reforçar o grupo A e B. }\end{array}$ \\
\hline $\begin{array}{l}\text { 9-PEREIRA } \\
\text { Sebastião, dos } \\
\text { Santos, E Lou- } \\
\text { reiro (2004) }\end{array}$ & $\begin{array}{l}\text { PNADs } 1992 \\
\text { e } 2001 \text { com } \\
\text { dummys para } \\
\text { crédito e } \\
\text { modelo de } \\
\text { regressão de } \\
\text { efeitos fixos. } \\
43.000 \text { produ- } \\
\text { tores }\end{array}$ & $\begin{array}{l}\text { O efeito do crédito é } \\
\text { negativo ou residual } \\
\text { na renda do produtor. } \\
(-0,11 \text { e com OLS : - } 0 \text {, } \\
\text { 2). que pode ser des- } \\
\text { viada para o consumo. } \\
\text { Mesmo } \\
\text { na região sul. }\end{array}$ & $\begin{array}{l}\text { a) Negociação através } \\
\text { de empresas e coopera- } \\
\text { tivas agrega maior valor. } \\
\text { Importância da existência } \\
\text { de crédito para a comer- } \\
\text { cialização. b)Cada ano } \\
\text { adicional de educação } \\
\text { incrementa em média } 6 \% \\
\text { a renda do trabalhador. }\end{array}$ \\
\hline $\begin{array}{l}\text { 10- GASQUES, } \\
\text { José Garcia et al } \\
(2005)\end{array}$ & $\begin{array}{l}\text { Dados IBGE } \\
\text { e PRONAF de } \\
\text { crédito em } \\
\text { municípios }\end{array}$ & $\begin{array}{l}\text { Os resultados não } \\
\text { permitem dizer que } \\
\text { haja uma relação } \\
\text { entre taxa de cresci- } \\
\text { mento do crédito e } \\
\text { taxa de crescimento } \\
\text { da população total. A } \\
\text { taxa de crescimento da } \\
\text { população rural tem } \\
\text { baixa probabilidade de } \\
\text { ser influenciada pelo } \\
\text { crédito do PRONAF. }\end{array}$ & $\begin{array}{l}\text { Tendência de concen- } \\
\text { tração do crédito em (mi- } \\
\text { cro) regiões homogêneas } \\
\text { entre si do ponto de vista } \\
\text { da absorção dos recursos } \\
\text { do programa (High- } \\
\text { High), com significância } \\
\text { estatística em particular } \\
\text { na Região Sul. Os valores } \\
\text { aferidos através da } \\
\text { distribuição do PRONAF } \\
\text { no período } 2000 \text { a } 2004 \\
\text { mostram ter havido um } \\
\text { aumento da cobertura } \\
\text { geográfica do programa. }\end{array}$ \\
\hline $\begin{array}{l}\text { 11- NUNES, Side- } \\
\text { mar et al (2004) }\end{array}$ & $\begin{array}{l}\text { Pesquisa de } \\
\text { Campo com } \\
\text { Conselhos de } \\
\text { Desenv. Rural }\end{array}$ & $\begin{array}{l}\text { PRONAF Infra: Na } \\
\text { maioria dos casos, os } \\
\text { recursos financeiros } \\
\text { do programa foram } \\
\text { aplicados de forma } \\
\text { inadequada, e não } \\
\text { conseguiram fazer } \\
\text { com que os Conselhos } \\
\text { articulassem processos } \\
\text { de desenvolvimento } \\
\text { rural. }\end{array}$ & $\begin{array}{l}\text { Tende a representar } \\
\text { um novo rearranjo nas } \\
\text { relações de } \\
\text { poder, por representar } \\
\text { uma nova disputa por } \\
\text { espaços. }\end{array}$ \\
\hline
\end{tabular}




\begin{tabular}{|c|c|c|c|}
\hline $\begin{array}{l}\text { 12- OLALDE, } \\
\text { Alicia Ruiz } \\
\text { (2005) }\end{array}$ & $\begin{array}{l}45 \text { sistemas } \\
\text { agroflorestais } \\
\text { do Sul da } \\
\text { Bahia }\end{array}$ & $\begin{array}{l}85 \% \text { disse que as } \\
\text { atividades financiadas } \\
\text { tiveram desempenho } \\
\text { ruim, } 40 \% \text { avalia mal } \\
\text { a experiência, mas } \\
80 \% \text { gostaria de rece- } \\
\text { ber o crédito de novo. } \\
\text { Usaram para consumo, } \\
\text { não se capitalizaram } \\
\text { e têm problema para } \\
\text { pagar. }\end{array}$ & $\begin{array}{l}\text { Assistência Técnica } \\
\text { Tradicional (monocul- } \\
\text { tura). } \\
\text { Falta de estrutura de } \\
\text { comercialização. Pre- } \\
\text { cisa-se de Planejamento } \\
\text { do desenvolvimento re- } \\
\text { gional, comercialização } \\
\text { e agregação de valor. }\end{array}$ \\
\hline $\begin{array}{l}\text { 13- MATTEI, L } \\
(2006)\end{array}$ & $\begin{array}{l}100 \text { municípios } \\
\text { que mais } \\
\text { receberam } \\
\text { PRONAF entre } \\
2000 \text { e } 2004\end{array}$ & $\begin{array}{l}\text { Em } 69 \text { municípios } \\
\text { ocorreu aumento do } \\
\text { PIB agropecuário. } \\
\text { A produção total au- } \\
\text { mentou em } 86 \% \text {. } \\
\text { Em } 72 \text { deles, a área } \\
\text { colhida aumentou. } \\
\text { Em } 81 \% \text { dos mu- } \\
\text { nicípios, as contrata- } \\
\text { ções superaram as } \\
\text { demissões. } \\
\text { Elevação da arrecada- } \\
\text { ção em } 83 \text { municípios. }\end{array}$ & $\begin{array}{l}\text { Apenas dois produtos } \\
\text { apresentaram tendência } \\
\text { significativa de cresci- } \\
\text { mento } \\
\text { dos preços: soja e man- } \\
\text { dioca. } \\
\text { Esse comportamento } \\
\text { dos preços agrícolas } \\
\text { sugere que a variável } \\
\text { preço exerce bem } \\
\text { menos influência na } \\
\text { definição da expansão } \\
\text { da produção agrícola, } \\
\text { comparativamente a } \\
\text { outras variáveis, como é } \\
\text { o caso da } \\
\text { disponibilidade de } \\
\text { crédito. }\end{array}$ \\
\hline
\end{tabular}

Pode-se perceber que, das 13 avaliações efetuadas no decorrer do processo de implementação do PRONAF, cinco revelaram resultados positivos, duas resultados ambíguos e seis negativos.

Entre as pesquisas que mostraram resultados positivos, dois (2) são muito antigas (IPEA, LUMEM) e uma trata de uma região pequena (FAVERO). As outras duas positivas (Sacco dos Anjos e a de Mattei) são mais recentes e são de âmbito estadual ou nacional. A pesquisa de Mattei, entretanto, usa dados secundários que permitem fornecer apenas indicadores indiretos de sucesso do PRONAF na produção, emprego, arrecadação etc.

Várias pesquisas de âmbito nacional revelaram resultados negativos em termos de impacto. A pesquisa da FECAMP fez um número con- 
siderável de entrevistas (1994) em vários estados e as de Magalhães, embora de âmbito regional (Pernambuco e Paraná) também entrevistou um número grande de agricultores (6.500). As três pesquisas tiveram grupos de controle em suas amostras.

Estas pesquisas transmitem a idéia de que o PRONAF teria piorado a situação dos beneficiários de crédito em relação aos que não tiveram.

As outras avaliações negativas, ou são muito restritas (Olalde), usaram apenas dados secundários (Pereira) ou se referem ao assunto do PRONAF Infraestrutura (Nunes) que não é parte desta avaliação.

A avaliação de Feijó, embora bastante negativa para os anos prévios a 2000, sugere que o programa teria começado a surtir impacto produtivo após essa data.

O trabalho de Gasques desmistifica a idéia de que o PRONAF estaria contribuindo a reverter à tendência de esvaziamento do setor rural. Isto teria acontecido se, por efeito do crédito, a população rural dos municípios beneficiados pelo PRONAF tivesse aumentado, o que não foi comprovado.

Os resultados em termos de melhora da renda e das condições de vida registrada pelas pesquisas disponíveis são bastante tênues. O nulo ou pequeno aumento da renda dos beneficiários do crédito do PRONAF redunda, logicamente, na dificuldade em pagar os créditos do PRONAF uma vez vencidos, como pode se observar na tabela que segue:

Tabela 7 - Créditos em atraso do PRONAF Região NORTE²

\begin{tabular}{|l|l|l|}
\hline Linha do PRONAF & $\begin{array}{c}\text { Percentual com } \\
\text { Atraso Risco FNO }\end{array}$ & $\begin{array}{c}\text { Percentual com Atraso } \\
\text { Risco Compartilhado }\end{array}$ \\
\hline A & 5 & - \\
\hline A/C & 15 & 41 \\
\hline B & 3 & - \\
\hline C & 48 & 11 \\
\hline D & 33 & 12 \\
\hline E & - & 1 \\
\hline
\end{tabular}

BASA. Sistema de Controle de Operações.

\footnotetext{
${ }^{2}$ Não foi possível conseguir dados sobre atrasos e renegociações para as demais regiões do país, apesar dos insistentes pedidos realizados ao BB e ao BNB.
} 
Percebe-se na tabela acima que o atraso é maior quando o risco é do Tesouro (chegando a $48 \%$ no caso do PRONAF C). No entanto o grupo A/C também registrou alto índice de atraso mesmo com risco compartilhado entre o Tesouro e o banco. Dados do Ministério de Integração Regional referido aos Fundos Constitucionais da região Norte mostram índices de inadimplência bastante altos 2004: PROCERA: 42,6\%, PRONAF A: 3,4\%, PRONAF C: $8,1 \%$, PRONAF D: $4,2 \%$.

Segundo o Relatório das Dívidas Rurais de janeiro de 2004, preparado por um grupo de gestores da Secretaria do Tesouro Nacional, a inadimplência do custeio teria sido de 1,6 \% nos grupos $B, C, D$, ou seja, bastante baixa. Isto ocorreria porque o Crédito do PRONAF ao ser controlado por organizações de agricultores e de assistência técnica e extensão rural, por meio da Declaração de Aptidão, impõe exigências bastante rígidas ao processo de seleção dos agricultores. Contribuiria, também, a prática do aval (garantia mais moral que efetiva) existente nesse processo seletivo.

Os dados de atraso e inadimplência não são muito altos, em media, porque parte dessas dívidas foi de fato renegociada obtendo-se, portanto, novos prazos de vencimento, o que oculta o verdadeiro atraso dos créditos. O total da renegociação de dívidas, segundo dados do Tesouro Nacional (Gasques, et al.) ascendem a R\$ 22 bilhões, incluindo as renegociações do PRONAF e outras despesas do governo com 11 fundos e programas: Securitização, Fundos Constitucionais, Recoop, tanto da agricultura familiar como da patronal.

Entre os fatores descritos nas pesquisas que influenciaram negativamente o processo de geração de renda dos agricultores, impedindo, portanto, que se viabilizasse o reembolso dos empréstimos, destacamse os seguintes:

1) Falta de Assistência Técnica ou baixa qualidade da AT: Os rendimentos previstos nos projetos são calculados a partir de coeficientes técnicos distantes da realidade do pequeno agricultor. Este, depois da safra, geralmente verifica que a maioria das atividades em que foram aplicados os recursos do crédito na região não acompanhou a previsão. Conseqüentemente, os agricultores passam a ter dificuldades para devolver os empréstimos.

As divergências acontecem tanto entre a previsão de evolução de pre- 
ços dos projetos em relação à realidade, que sempre são inferiores, como nos custos de produção, que acabam sendo sempre superiores aos previstos. Há também casos em que os rendimentos previstos no projeto não foram alcançados devido à quebra de safra por fatores climáticos ou por problemas fitossanitários que tampouco eram previstos nos projetos.

Além da deficiência técnica, o tamanho do corpo técnico das instituições oficiais de assistência técnica, segundo Olalde, Alicia (2005) seria insuficiente para dar orientação individualizada aos agricultores. Os escritórios locais contam com dois ou três técnicos para dar orientação a uma área de abrangência de vários municípios, com um público alvo de mais de 5.000 agricultores. O resultado é a padronização dos projetos e o escasso acompanhamento técnico, restrito na maioria dos casos a visitas de fiscalização para a liberação de novas parcelas, além de algumas atividades de capacitação (Olalde, op cit).

2) Dificuldades no gerenciamento dos recursos do crédito. Em alguns casos, os recursos não são aplicados integralmente na atividade programada. O agricultor realiza economias na adubação e tratos culturais, por exemplo, seja porque existem muitas carências de investimentos em outras atividades produtivas na mesma propriedade agrícola ou porque ele não tem como sustentar a família até que o projeto comece a dar retorno, e acaba tirando parte do sustento do crédito rural. Isto diminui a possibilidade de pagamento dos créditos deixando muitos agricultores endividados, o que psicologicamente é desastroso para eles.

3) Falta de visão sistêmica dos técnicos: Existem divergências entre a avaliação feita pelos técnicos e a prática dos agricultores: " $O$ técnico não queria que plantasse nada com o guaraná, só ele purinho. Se tivesse plantado outro cultivo no meio, bem que a gente estava feliz" (agricultor da comunidade Marimbondo). Ou, nas palavras de outro agricultor da mesma comunidade: "A CEPLAC não aceitou plantar nada dentro, depois que a pimenta começou a morrer foi que eles mandaram plantar coisa dentro. Estou replantando tudo com seringa e cacau. Já era para estar replantado." (Alicia Ruiz Olalde, pág. 8)

4) Falta de integração nos mercados, de estrutura de comercialização e de agregação de valor: A visão clássica dos técnicos educados na revolução verde era a de produzir muito com ganhos crescentes de produtividade, sendo necessário para isso pedir empréstimos que viabilizassem 
a compra dos pacotes tecnológicos recomendados. Muitas vezes a produção e a produtividade aumenta, mas os preços caem. O ganho de produtividade é assim captado pelos intermediários financeiros e comerciais. Na realidade, os agricultores devem olhar primeiramente para os mercados, ver seus sinais e produzir aquilo que tem demanda e perspectivas de integração agroindustrial. Depois, pensar-se-ia na tecnologia e finalmente no crédito que porventura for necessário para adotar essa tecnologia. A motivação principal para esta virada de olhares é a necessidade de garantir o máximo de apropriação de renda e de valor pelos agricultores familiares, mas para isso é necessário compreender bem a dinâmica dos mercados e não se deixar iludir por promessas de crédito barato e preços bons.

Apesar disso existem evidências concretas que os recursos do PRONAF, embora tenham propiciado pequena ou nula melhora na renda monetária dos agricultores familiares (dependendo da pesquisa de que se trate), teriam contribuído na ampliação da capacidade produtiva dos agricultores familiares propiciando aumento de área com culturas de subsistência que significam menor dependência de alimentos vindos de fora da unidade produtiva.

O próximo Censo Agropecuário do IBGE (2006), ao permitir a comparação com o de 1996, provavelmente mostrará esta tendência e permitirá comprovar de forma definitiva o impacto do PRONAF na renda e na produção dos agricultores familiares.

As políticas públicas, quando massificam suas metas, geralmente afrouxam o controle de qualidade e a eficiência diminui. Isto estaria acontecendo com o Bolsa Família, por exemplo, que afrouxou o controle sobre o condicionamento de assistência a escola para receber a bolsa, em função das dificuldades cadastrais surgidas quando se aumentou a escala do programa.

No caso do PRONAF abandonou-se a visão de sistemas que originalmente era defendida por parte dos técnicos e assessores, e que implicava em relacionar uma tipologia de produtores com uma tipologia de sistemas produtivos. O refinamento dessa classificação permitiria definir melhor os produtos dentro dos sistemas que precisariam de reforço com crédito, terra ou tecnologia. Procurava-se avaliar uma região e diagnosticar quais seriam as necessidades de apoio diferenciadas por tipo de produtor e por tipo de sistemas; num plano de desenvolvimento 
regional que contemplasse as necessidades dos agricultores familiares em relação ao seu contexto social e produtivo.

Para isso precisar-se-ia de uma AT de bom nível que seguisse uma visão sistêmica e participativa ao invés de trabalhar, apenas, caracterizando déficits de insumos para produtos isolados. Infelizmente o PRONAF fez apenas a classificação dos tipos de produtores (classes de renda) e deixou sem fazer a tipologia de sistemas produtivos que deveriam ser apoiados.

Ao se tentar fazer uma avaliação do PRONAF surge a dificuldade de compreender até que ponto algumas cadeias produtivas teriam sido fortalecidas no Brasil e outras não e quais seriam as necessidades de crédito para as cadeias selecionadas como prioritárias pelo governo e a sociedade, porque isto não foi previsto pelas autoridades que planejaram o programa.

Uma das tentativas de visualizar a agricultura familiar como parte das cadeias produtivas foi feita por Guilhoto e Silveira (2005). Eles desenvolveram uma metodologia para o cálculo do PIB do agronegócio familiar baseado na idéia de que, à semelhança da estimativa do PIB do agronegócio total, o PIB do agronegócio familiar resulta da soma de quatro agregados principais: insumos, agropecuária, indústria e distribuição. (Guilhoto, et al. 2005). Com base nesta metodologia, o segmento familiar da agropecuária brasileira e as cadeias produtivas a ela interligadas responderiam, em 2003, por 10,1\% do PIB brasileiro.

Esta tentativa de dimensionar o tamanho da cadeia agroindustrial familiar parte do suposto que as empresas familiares são donas ou fazem parte do complexo agroindustrial a jusante e montante do setor produtivo na mesma proporção em que produzem na agricultura. Desta forma, fez-se a transposição mecânica da participação de 37,9\% na produção agrícola (dados FAO/INCRA) para o cálculo na produção nos setores do complexo agroindustrial, obtendo-se assim o valor de 10,1\% do PIB.

Esta tentativa, embora importante, porém sem base empírica, revela justamente a necessidade que existe de caracterizar com dados de campo as cadeias produtivas da agricultura familiar, procurando saber as fortalezas e fraquezas que cada tipo de produtor tem em cada tipo de cadeia, no tocante a graus de concentração agroindustrial, fixação de preços, normas contratuais, fluxo de financiamento existente na cadeia, regularidade das compras e do fluxo de insumos, tecnologias disponí- 
veis, características da comercialização e condições de integração no processamento, ganhos de intermediação excessivos ou normais etc.

Infelizmente, ao invés de seguir uma metodologia sistêmica que priorizasse algumas cadeias produtivas em algumas regiões do país, caiu-se no crédito de balcão, nas pontas, sem avaliação das cadeias produtivas. Como os recursos sempre são escassos nunca será possível atender satisfatoriamente todo mundo e, ao tentar fazê-lo indiscriminadamente, atomizam-se os recursos, provocando desperdício e ocasionando efeitos produtivos e sociais pouco definidos. Não se trata, portanto, de implementar políticas de curto prazo em função apenas de objetivos sociais de ordem individual, mas de resgatar e fortalecer, entre outras coisas, as cadeias produtivas que formam a coluna vertebral de um grupo de municípios, de forma a ganhar em competitividade e poder, assim, combater a pobreza rural de forma efetiva.

\section{Conclusões}

O PRONAF causou um impacto considerável na agricultura brasileira na década de 1990 e também entre 2000 e 2005. Por esse motivo e por se tratar também de um programa caro (em termos financeiros) para a sociedade, ele deve ser permanentemente revisto, avaliado e aperfeiçoado de forma a que não perca sua característica original de proteger de forma eficiente um segmento da população rural que tem uma importante participação na vida nacional.

Um dos principais impactos foi o de permitir que os agricultores familiares investissem em sua atividade e ampliassem as áreas plantadas. As avaliações realizadas até o presente momento não são conclusivas, entretanto, no que diz respeito ao impacto na renda e a melhoria do padrão de vida da população rural beneficiada. O próximo Censo Agropecuário do IBGE (2006) permitirá comparar os resultados atuais com os indicadores calculados em 1996 (FAO/INCRA), trazendo dessa forma elementos de juízo objetivos para avaliar o desempenho dos agricultores familiares na última década.

Um dos pontos críticos do programa diz respeito à capacidade de pagamento de crédito por parte dos beneficiados, que não parece ter sido assegurada convenientemente pelas autoridades, já que precisa- 
ram conceder contínuas renegociações e resseguros dos empréstimos que ficaram em atraso ou estavam ficando inadimplentes.

É necessário, portanto, rever a institucionalidade e a forma de operação do PRONAF a fim de reforçar a disciplina financeira, induzir os mutuários a buscarem o máximo de eficiência na utilização dos recursos e melhorar o sistema de políticas complementares necessárias para promover a efetiva consolidação do agricultor familiar. Neste sentido é fundamental introduzir responsabilidades ao longo de toda a "cadeia" do PRONAF, fazendo com que os vários atores - SAF, Bancos, assistência técnica, Comissões Estaduais e agricultores - sejam de fato responsáveis pelos seus atos e, portanto, compromissados com os resultados.

Dever-se-ia pensar também se os rebates e fortes subsídios na parte do capital do crédito deveriam ser mantidos. De fato um crédito como o PRONAF A e o B nos quais ate $40 \%$ do valor do principal pode ser perdoado pode confundir o beneficiário sobre o que é um crédito ou doação, deseducando-o no futuro quando ele tenha que enfrentar empréstimos comerciais sem rebates deste tipo. Talvez seja o caso de renomear os programas, chamando alguns de transferências diretas (juntando-os com o Bolsa Família) e mantendo o conceito de crédito para aqueles casos nos quais se trate efetivamente disso. Nesses casos, as condições devem ser respeitadas sem macular o papel dos Bancos enquanto agentes financeiros.

Atualmente, não existem, por exemplo, mecanismos de controle de saldos devedores por parte dos Bancos nem esses saldos são informados de forma transparente à sociedade (de forma agregada).

Surge, em função disso, a necessidade de recriar a institucionalidade e de impor mecanismos de controle social mais efetivos. Uma alternativa seria, como se viu anteriormente, a de dirigir o crédito a algumas cadeias produtivas selecionadas a priori em algumas regiões, que contassem com Planos de Desenvolvimento Territoriais bem elaborados.

\section{Referências bibliográficas}

ABRAMOVAY, Ricardo \& VEIGA, Eli da (1998): Novas Instituições para o Desenvolvimento Rural: o caso do Programa Nacional de Fortalecimento da Agricultura Familiar (PRONAF). Brasília: IPEA: abril, 1998. 51p. (Texto para Discussão n.641) 
ABRAMOVAY, R. (2002) "O peso da intermediação bancária no PRONAF” - Gazeta Mercantil - 17/04/02 p. A3.

BANCO DO BRASIL MIR (Ministério de Integração Regional): FCO Fundo Constitucional do Centro Oeste. www.mir.org.br

BITTENCOURT, Gilson A. \& ABRAMOVAY, Ricardo. Inovações institucionais no financiamento à agricultura familiar: o Sistema Cresol. Revista Economia Ensaios. São Paulo: vol.16, n.1, 2003.

BUAINAIN, Antônio M. \& SOUZA FILHO, Hildo M (1998). PROCERA: Impactos Produtivos e Capacidade de Pagamento. Projeto FAO/INCRA - Relatório Final. Campinas, novembro/1998. www.mda/incra/fao.org

FAO/INCRA. Diretrizes de Política Agrária e Desenvolvimento Sustentável. Resumo do Relatório Final do Projeto UTF/BRA/036. Carlos Guanziroli (coord.). Segunda versão. março/1995.

FAO/INCRA/MDA (2000). Novo Retrato da Agricultura Familiar: o Brasil Redescoberto. Silva Cardim (FAO) e Carlos Guanziroli (INCRA) (coord). Brasília: Ministério do Desenvolvimento Agrário e Instituto Nacional de Colonização da Reforma Agrária, fevereiro/2000.

FAVERO, L, ALVES (2002): Análise De Desempenho Do Programa Nacional De Fortalecimento Da Agricultura Familiar - PRONAF Em Pernambuco. Anais do XL Congresso SOBER, julho/2002 Anais XL. Passo Fundo RS.

FECAMP (2002)- Fundação De Economia De Campinas E Convênio Pct/ Iica-PRONAF. Estudos de Caso em Campo para Avaliação dos Impactos do Pronaf. Campinas, outubro/2002. Disponível em: www.pronaf.gov.br FEIJÓ, R. The impact of a family farming credit programme on the rural economy of Brazil. Anais da ANPEC, XXIX Congresso de Economia. Salvador, 11 a 14 de dezembro de 2001.

GASQUES,J.M; VILAVERDE,C; Bastos,E: (2000): Gasto Público na Agricultura. Retrospectiva E Prioridades. Ministério de Agricultura, Pecuária e Abastecimento (MAPA).ASSESSORIA DE GESTÃO ESTRATÉGICA.

GASQUES José Garcia et al. (2005): Agricultura familiar - PRONAF: análise de alguns indicadores. XVIII Congresso SOBER, julho/2005. Ribeirão Preto SP 
GUANZIROLI, Carlos et al.: Agricultura Familiar e Reforma Agrária no Século XXI. Rio de Janeiro: Garamond, 2001. 288p.

GUILHOTO,J; Silveira,F; Azzoni,C (2005) A Importância Do Agronegócio Familiar No Brasil. XVIII Congresso SOBER, julho/2005. Ribeirão Preto SP

LUMEN INSTITUTO DE PESQUISA - PUC MINAS. Relatório da Pesquisa de Análise da Execução do Programa de Fortalecimento da Agricultura Familiar (PRONAF) em Minas Gerais. Belo Horizonte, outubro/1997.

MAGALHÃES, André Matos, et al. (2005): "The family farm program in Brazil: the case of Parana”. XVIII Congresso SOBER, julho/2005. Ribeirão Preto SP

MAGALHÃES, André Matos, et al. (2005): "The family farm program in Brazil: the case of Pernambuco". XVIII Congresso SOBER, julho/2005. Ribeirão Preto SP.

MARQUES MORUZZI (2004): Concepções concorrentes em torno das políticas públicas de apoio à agricultura familiar: uma releitura sobre a construção do PRONAF. Anais XVII Congresso da SOBER, julho/2004. Cuiabá MT.

MATTEI, L (2005) : Impactos do PRONAF: Análise de Indicadores. Série Estudos 11 NEAD. MDA.

MINISTERIO DE INTEGRAÇAO NACIONAL: Fundos Constitucionais de Financiamento, Secretaria de Políticas de Desenvolvimento Regional. Sistema de Informações Gerenciais SIG Ano IX Nº 32, dezembro/2004 (2004).

NUnes, S, PAGLIOSA, H; CAMPOS, C(2004): Políticas Públicas Descentralizadas Como Estratégia De Gestão E Monitoramento Social: O Caso Do Pronaf Infra-Estrutura. Anais XVII Congresso da SOBER, julho/2004. Cuiabá MT.

OLALDE, A,R (2005): PRONAF, Sistemas Agroflorestais e Desenvolvimento Sustentável no Baixo Sul da Bahia. Anais XLIII Congresso da SOBER, 2005. Ribeirão Preto.

ORTEGA, ANTONIO CÉSAR E MENDONÇA, Nilton (2005): “Estratégias de desenvolvimento territorial rural: governo FHC $\mathrm{X}$ governo Lula”. Paper apresentado no Congresso da SOBER de Ribeirão Preto. 2005 
PEREIRA S, FIGUEIREDO, A, e LOUREIRO, R. (2004): Avaliação da Política de Agricultura Familiar: Uma abordagem de efeito-fixo. XVII Congresso da SOBER, julho/2004. Cuiabá - MT.

PETRELli C,V; Ortega, A. (2002): PRONAF: Programa Nacional De Fortalecimento Da Agricultura Familiar - Qual O Seu Real Objetivo E Público Alvo? Anais do XL Congresso da SOBER, Passo Fundo, RS.

PETRELli C,V; Silva, F (2004): O novo desenho do Financiamento Agrícola e as dificuldades para os produtores não integrados. Anais XVII Congresso da SOBER, julho/2004. Cuiabá - MT.

PETRELLI C,V; Silva, F (2005): Análise das liberações recentes de recursos do PRONAF - uma mudança na lógica de distribuição? XVIII Congresso SOBER, julho/2005. Ribeirão Preto SP.

PRONAF (2002): Relatório Institucional do PRONAF. SAF/MDA. www.mda/saf.org

REZENDE, Gervásio C. de (1999). Programa de Crédito Especial para Reforma Agrária (PROCERA): Institucionalidade, Subsídio e Eficácia. Rio de Janeiro: IPEA: maio/1999. 22p. (Texto de Discussão n.648).

SACCO DOS ANJOS, Flavio (FECAMP) et al. (2004): Agricultura familiar e políticas públicas: o impacto do PRONAF no Rio Grande do Sul. XVII Congresso da SOBER, julho/2004. Cuiabá - MT.

SCHNEIDER,S; Westphalen,F; Gazolla,M(2005): AS DUAS “CARAS” DO PRONAF: Produtivismo ou fortalecimento da produção para autoconsumo?. XVIII Congresso SOBER, julho/2005. Ribeirão Preto SP.

SECRETARIA DE DESENVOLVIMENTO RURAL DE SC (2002): Instituto CEPA/SC Avaliação do PRONAF Infra estrutura e Serviços. 2002.

TARTARUGA, Iván G. Peyré (2005): O conceito de território para a análise do desenvolvimento rural. Paper apresentado a SOBER de Ribeirão Preto.

TEIXEIRA, Erly, Castro,E (2004): Efeitos dos gastos com a Equalização das Taxas de Juros do Crédito Rural na Agricultura Brasileira. Anais XVII Congresso da SOBER, julho/2004. Cuiabá MT.

Recebido em agosto de 2006 e revisto em outubro de 2006 